From Text E-Books to Digitally Enriched E-Books in Folklore Education Using the iPad

\author{
Alexandros Kapaniaris \\ PhD Candidate in Folklore, Department of Science Education and Educational Design, \\ University of the Aegean, Rhodes, Greece \\ Email: a.kapaniaris@aegean.gr \\ Maria Gasouka \\ Assistant Professor in Folklore and Gender, Department of Science Education and Educational Design, \\ University of the Aegean, Rhodes, Greece \\ Email:mgasouka@rhodes.aegean.gr \\ Dimitris Zisiadis \\ Research Associate, Department of Computer \& Communication Engineering, \\ University of the Thessaly, Volos, Greece \\ Email: dimitris@uth.gr

\section{Eleni Papadimitriou} \\ Teacher of Preschool education, Department of Early Childhood Education, \\ University of the Thessaly, Volos, Greece \\ Email: elpapadi@uth.gr

\section{Evangelia Kalogirou} \\ M.Ed. Candidate, University of Nicosia, Cyprus \\ Email: lilia.kalogirou@yahoo.gr
}

Doi:10.5901/mjss.2013.v4n11p316

\title{
Abstract
}

From the first text electronic books (e-books) to the latest digitally enriched e-books a long distance has been covered. E-book market blossoms while technologies for enhanced e-book development advance rapidly, leading to a surge in the demand for enhanced e-books, especially in education. This paper refers to electronic books and the way simple text e-books can be transformed into enriched e-books. An attempt is also made to highlight the role of enriched e-books in folklore education. Within the above framework, taking into account the rapid growth of electronic books and the availability of several development tools the following approach was adopted: a) Definition of an e-book taxonomy referring to the types and attributes of e-books in order to provide a helpful guide for those who choose to introduce e-books in their teaching meaningfully, b) Specification of the development process of enriched e-books through several applications such as the iBook for $\mathrm{iPad}$, the most prominent candidate for e-book enhancement, c) Identification of the specifications and the process to create learning objects that can be used as enriching digital resources in enriched e-books.

Keywords: enriched e-book, text e-book, folklore, learning object, taxonomy, iBook, iPad

\section{Introduction}

A significant amount of time has passed since the introduction of electronic books (e-book) and e-book readers. However, the development of e-book devices and standards intensifies from 2004 onwards. Electronic book is referenced in the literature as ebook, e-textbook, web textbook, online textbook, digital textbook, ePUB, Portable Document Format (pdf), Mobipocket etc. and indicates publication of a printed book in electronic form. E-book can be 
read in a desktop computer, laptop, handheld computer (handheld device, PDA: Portable Digital Assistant) and standalone devices (Dedicated Reading Device, tablet PC, e-book reader, iPad) (Pedagogical Institute, 2009).

The educational community facing the new trend of digital reading is obliged to participate in an international dialogue for digital books, digital readers and the educational use of new learning tools. There are concerns on the possibility of reading books from digital devices, on the educational benefit of this new form of reading and finally on whether digital books will serve students and educators needs. Especially in recent years, the emergence of enriched ebooks feeds this international debate about digital reading by bringing pedagogical design at the focus of discussions. As a consequence, the development of learning objects and their integration in enriched e-books in order to support learning experiences and teaching scenarios gradually comes to the centre of attention. So, we move away from the simple ebook to digitally enriched e-book, which mobilizes more, senses (vision, hearing, touch), provides multiple sources (Internet), offers composition control capabilities (notes, bookmarks, advanced search) and constantly updates its contents with the introduction of new versions.

In the educational sector, especially in folk culture, such books are tools to record, update, distribute and disseminate educational material on folk culture. Moreover, considering electronic readers' portability we can easily understand the added value of enriched e-books on student visits to museums, cultural sites, fieldwork folklore research etc. Taking into account the interface between Internet (links to material folk culture), web 2.0 applications (authoring tools) and enriched e-books, then we can certainly reflect on ways to create learning experiences enhanced with learning resources based on folk culture teaching scenarios.

\section{Digital Reading and Folklore Education}

Digital books and digital reading in general have emerged as an important issue in the education community. There are concerns regarding digital reading feasibility and convenience and how useful digital reading can be for both educators and students. Digital reading both as a concept as well as everyday practise is not new to the new generation of students and teachers. Students are accustomed to digital reading through the Internet (e.g. Facebook), mobile phone, PDA and other portable devices, making digital reading an everyday practise. However the mood differs when reading literature in print, browsing the web or performing another task. In the end the prevailing factor in what is exciting for anyone is the content itself and not the media. (Gasouka, Kapaniaris, Arvanitidou, Foulidi \& Raptou, 2013; Kapaniaris, Vainas, Papadimitriou \& Valatsou, 2010).

Some of the key characteristics of e-book reading on digital devices are the following: a) promotion of reading, as especially young people spend most of their time in front of screens as they are accustomed to this type of reading, $b$ ) production of books on hot issues and events in a short time, c) quick content updates for error correction and additional information, d) portability, as reading device can store the contents of a small library, e) people with special needs can benefit, as visually impaired can easily adopt text size and font to meet their needs (Kapaniaris et al., 2010).

Digital reading can be exploited in folklore education through simple and complex learning object development. Learning object development provides the raw material for the digital enrichment process of e-books on folk culture in HTML or any other format (Gasouka et al., 2013).

\section{E-book Evolution}

E-books are a new trend in education. E-book penetration boosted following evolution of multimedia and the Internet along with enhanced portable e-book reader availability. As Guenette, Trippe, \& Golden (2010) mention except for some powerful interactive systems, there is a shortage of enriched digital books that creates uncertainty of their future deployment. The enriched e-book timeline starts at 1990, when Robert Abel founded «Synapse Technologies», a pioneering company for mass media interactive applications, which produced innovative education programs for IBM, including the application «Columbus: Discovery, Encounter and Beyond». Nowadays the evolution of enriched e-book is constant with the majority of them concerning the iPad (Guenette, Trippe, \& Golden, 2010).

By introducing high-resolution touch technology, e-book reading has been enhanced through embedded multimedia including narration, music, animation, video and games. Enriched e-books are a developing industry addressing tablet PC and smartphone markets. The majority of e-books are offered in epub format, which is satisfactory for text but inadequate for digital publications requiring precise layout or special formatting, as is the case with children and education books. A constantly increasing number of e-books embed multimedia applications especially in the children and education market (Jack and Beanstalk Aryars Animation, Toy Story by Disney, Cat in the Hat by 
Oceanhouse Media, Curious George by Iceberg Reader, and Our Choice by Push Pop Press). These interactive e-books feature animation, sounds for user login, zoom, embedded video and embedded mini-games, making the books more interactive and attractive compared to simple e-books and printed books (Mori et al., 2011; Vasileiou, Hartley \& Rowley, 2009).

\subsection{E-book Taxonomy}

Figure 1 provides an e-book taxonomy taking into account the device (desktop or mobile device), development technology and different levels of reading, interaction and exploration:

a) E-books in pdf, doc, docx or rtf format: created by free or commercial software, featuring fast and easy development but limited interaction.

b) E-books in html and epub format: created by html editors or free/commercial software, introducing a first level of interaction.

c) Flipbooks: created by free or commercial software in html, exe or swf format, featuring interaction through links in webpage resources.

d) Enriched e-books: created entirely in html, featuring high interactivity, exploration and reading.

e) eAnagnosis enriched e-books: created by pdf files using eAnagnosis software (www.e-anagnosis.com), featuring interaction, exploration and reading.

f) iBooks for iPad: enriched e-books for iPad created by iBooks Author software from Apple, featuring the highest levels of interaction, exploration and reading.

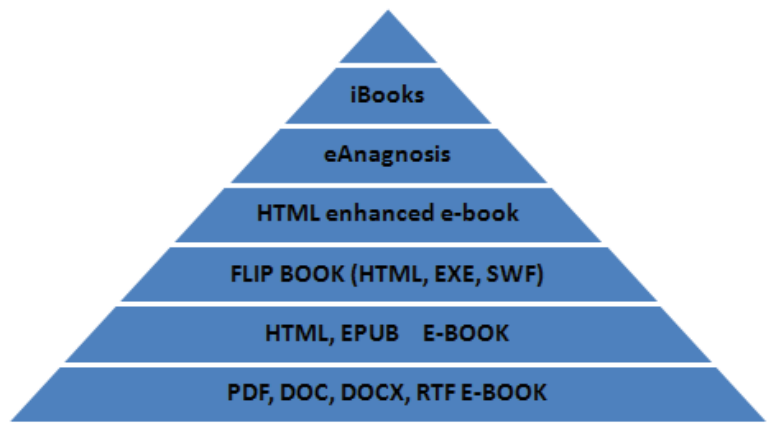

Figure 1: E-book taxonomy

\subsection{Enriched e-books}

Enriched e-book is defined as a digital form of a book in html, epub, or any other format (like iBook), digitally enriched with simple learning objects (Learning Assets) and complex learning objects (Learning Resources) with specially marked corresponding icons, mouse over enabled object icons and information on every learning object. Learning assets are image, simulation, text, experiment, sound, exploration, video, open activity, model, research activity and data representations while learning resources are education game, practice and training, evaluation applications, educational scenario - lesson plan, role play, glossary, reference guide, textbook, source-reference, webcast, webpage, blog, wiki and social media. (Kapaniaris \& Papadimitriou, 2012).

\subsection{Enriched e-books and Folklore Education}

Learning process in the folk culture area can be enhanced though the use of enriched e-books and generally enriched digital content for presentations, recording and imprinting folk culture views. Enriched e-books and enriched content can be read by special readers and various types of computers, thus enhancing the teaching of popular culture: a) in the classroom (cross thematic approaches), b) educational visits in museums, libraries and exhibition areas, c) fieldwork folk research, d) additional material in school project.

With the help of enriched digital media students have the opportunity to form a new perspective on fairy tales, 
myths, riddles, folk songs, folk art and traditional crafts in an interactive way where exploration, participation and the individual learning path is chosen by each student in a fairly constructive way. So students from passive receiver and serial reader of conventional books or sources become more active through interaction with a number of interactive elements, links, informative text pop ups, and by using the internet resources embedded in the enriched books gain the opportunity to participate in folk culture activities and games (Gasouka et. al., 2013).

\subsection{Enriched e-book Development}

The determining factors for the process of reading, exploring, interacting and generally enriching e-books are based on five key principles and are presented in Figure 2:

a) Technological framework for the hardware of the reading device (e-reader, iPad, tablet, personal computer).

b) Technological framework for the authoring software (html, eAnagnosis, iBook).

c) Depth of the enrichment process (icons linked to learning objects, internet links, links to internal resources glossary of terms).

d) Pedagogic/teaching framework of the book.

e) Learning object types that will be used in the authoring process (simple and complex learning objects).

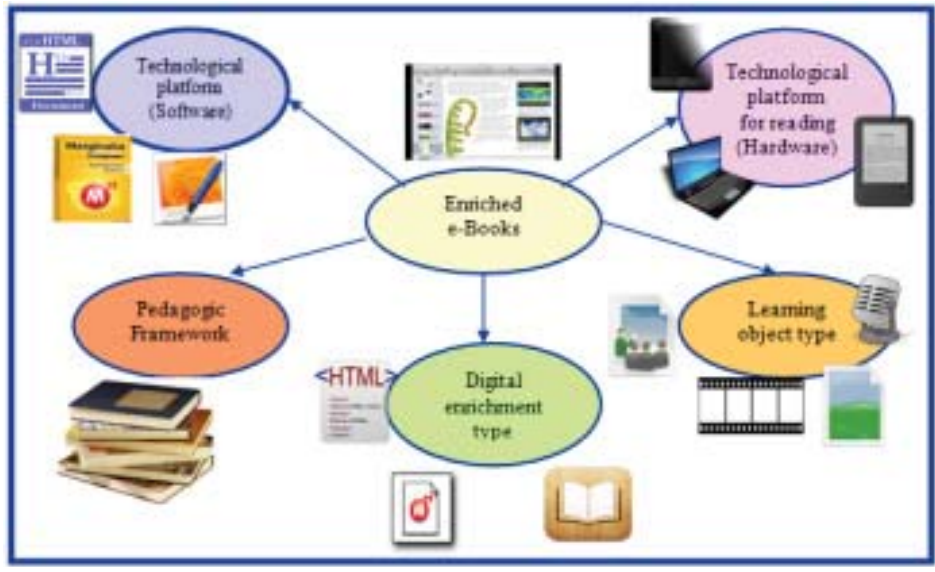

Figure 2: Enriched e-books, determining factors.

There are three authoring tools for enriched e-books: a) html language, b) iBooks Author by Apple and c) eAnagnosis, presented in Table 1 below. Learning object development of the learning objects to be used during the authoring process is a requirement for all three.

Table 1: Enrichment tools, reading devices.

\begin{tabular}{|l|l|l|}
\hline HTML editor & Apple iBooks Author & $\begin{array}{c}\text { e-anagnosis's Marginalia } \\
\text { (Composer \& Paspartu) }\end{array}$ \\
\hline http:/www.coffeecup.com/free-editor/ & http:/www.apple.com/ibooks-author/ & http://www.eanagnosis.com \\
\hline
\end{tabular}




\section{Learning Object Specifications}

During the design and development phase of learning objects the following technical and functional requirements must be taken into account:

- Learning objects must rely on some learning theory (constructivism, behaviourism) depending on the learning goal and the context of their use,

- Learning objects must provide added value to the learning process as well as the educational material with which they are combined,

- Learning objects must have an "Info" button which opens an informational card,

- Learning objects must have a "Help" button that provides convenient and readable instructions/help info utilization of the digital learning object,

- Learning objects must be created in a form that can be posted on the web or in another multimedia application (html, htm, swf, ppt, word, xml, flv, mp3 etc.),

- Learning objects must be compatible with the available browsers (IE, Mozilla Firefox, Opera, Google Chrome, Safari, etc.),

- Operation in relation to the dimension of the learning object in order to allow shadowbox operation,

- Learning object must be accompanied by Metadata, which are declared following its construction according to the standard,

- Technical requirements must be stated for the learning object operation (plug-in).

\section{Digital Enrichment through the iBooks Author for the iPad}

iBooks Author for iPad is a valuable option for authoring enriched e-books on folk culture by creating units and narrations, fairy tales, biographies, beliefs, crafts, myths, folk songs etc.

There are numerous features available in iBooks offered by iBooks Author software, such as: a) book opening (visible controls, image zoom, transition to a page, word search, table of contents view, add/delete bookmark), b) book commenting (add label, add/delete note, view all notes), c) appearance settings (fonts, zoom, page/text colour, contract, enable/disable justification and spelling).

One of the advantages of using iBooks Author for enriched book development is the organization options offered by the software on top of the interactive capabilities of the iPad. The tool enhances content through exploration, discovery, consolidation, presentation and practise/training. Movies, diagrams, presentations, galleries, 3D objects and chapter reviews are easily introduced, enabling students to utilize multiple senses concurrently through touch and multitouch gestures (tap, drag, pinch, swipe).

\subsection{Using iBooks to Develop Learning Experiences}

In order to take full advantage of the iBooks authoring capabilities in learning experience development, we need to clarify the notion of a «learning experience». A learning experience is more than developing an activity by using ICT to create satisfactory activities for the students that are effective, easily comprehended and flexible. It also needs to be useful in students' real life. The iBooks and their valuable features must be used to create learning experiences. So, one has to create the conditions to take advantage of multisensory experience and different interaction levels (Thomas, Carroll, Kop, \& Stocking, 2012).

Moreover, iBooks applications for iPad satisfy learning experiences and needs of particular schools by adapting school textbooks in order to achieve learning goals for a series of courses (Melhuish \& Falloon, 2010).

Thomas et al. (2012) suggest that research and development framework of a complete learning experience consists of four stages. First is the starting stage, where the area and the key goal of the learning research are defined. Specifically, users are identified, user purposes are clarified, context analysis is performed along with market research, and needs assessment and literature review. In the second stage requirements definition and structure definition are performed. Use analysis and determination, interactivity level definition, concept development, identification of cognitive and sensory directions, formulation of the research question, data mining, pedagogic analysis, scheduling based on learning and education process, development technology evaluation and plan finalization are all taking place during this stage. Transitioning is taking place during third stage, namely production control, installation and development of the learning process. Publication of text (content) with accompanying presentations, learning plan formulation along with 
overall evaluation and dissemination is taking place. The last stage concerns the creation of the learning experience upon its final plan, structure, testing and reviewing. In effect during this stage the standard material is developed following control and user experience evaluation. Moreover educational research is conducted (interviews, focus groups, ethnography) followed by analysis of the research results and discussion with teachers in order to complete the final deliverable (Thomas et al., 2012).

\section{2 iPad in Folk Teaching}

Mobile device technology and touchscreen development in tablets like the iPad offer new opportunities and novel approaches in education and folk culture. Folk culture extracurricular activities as well as visits to museums and cultural sites in conjunction with the use of iBooks may have a special impact in cognitive skills building (Jones et al., 2011).

The iPad apart from its portability is an ideal tool to use in rural cultural sites, allowing students to recall documents and enriched e-books in real time while keeping notes or accessing multiple learning object sources in a short time (Melhuish \& Falloon, 2010).

Moreover, iBooks offer the opportunity to comprehend complex concepts bringing together mobile technologies and the iPad with folk culture areas and concepts. It is quite impressive how students can use (multi) touch technology enhancing the museum experience with learning through gaming and social media. Children interaction with archived material through publications-reading applications for the iPad enhances the dialectical process not only in the classroom but also in cultural sites by combining digital gaming with raw material (Jones, et al., 2011).

\section{Conclusions}

Enriched e-books created by authoring tools such as iBooks, e-anagnosis, html techniques and other possible environments are expected to see higher growth in the future. The development rate and future of enriched e-books is associated with the rapid development of portable reading devices (tablet PC, iPad) and with new handling capabilities of e-books provided by the relevant reading software. All the above combined with portability, increased interactivity and incorporation of alternative sources of information and learning lead to expected growth of the enriched e-book market.

However, the use of technological tools (software \& hardware) itself never affected education and was not beneficial for the learning process. The new teaching framework that can be configured using enriched e-books demands specific pedagogical design based on authentic learning experiences, exploration, discovery and synthesis of learning materials. The challenge for the future of enriched e-books is whether such a tool can be successfully incorporated in designing instructional interventions and whether teachers and students can themselves become creators of material that can be incorporated into enriched digital books. Also, institutional stakeholders (Ministry of Education) are expected to formulate specific design and development specifications (pedagogical - teaching context) for enriched e-books to be used in education.

The example of Greece for primary and secondary education is the creation of enriched e-books (in html) and the «Photodentro» repository of learning objects (http://photodentro.edu.gr) as part of the digital school initiative (http://digitalschool.minedu.gov.gr). A similar ongoing effort is taking place in higher education through «Kalippos» (http://www.kallipos.gr), a very interesting project for enriched e-book development from the educational community on various subjects. Upon completion and use, evaluation of the above two efforts will be beneficial in designing similar initiatives.

\section{References}

Gasouka, M., \& Foulidis, X. (2012). New horizons of Folklore Studies - Conceptual Framework, Research, Gender, Internet and School. Athens: Sideris.

Gasouka, M., Kapaniaris, A., Arvanitidou, Z., Foulidi, X., Raptou, E. (2013), "Folk culture and digital enriched books: The case study of the digital enriched tool "E-ANAGNOSIS". In Gómez L., et. al. (Ed.), 7th International Technology, Education and Development Conference: (pp. 4176-4184). Valencia: International Association of Technology, Education and Development.

Guenette, D., Trippe, B., Golden, K. (2010). A Blueprint for Book Publishing Transformation: Seven Essential Processes to Re-Invent Publishing. Outsell's Gilbane Group: Research Report, 140-142.

Jones, S.J., Hall, L., Hilton, J., Fowler, J., Hall, M. Smith, P. (2011). Investigating the use of the ipad in heritage in education for children: impact of technology on the "History Detective" in a Victorian classroom role play activity. In IATED (Ed.), 4th International Conference of Education, Research and Innovations: (pp. 1262-1271). Madrid: International Association of Technology, Education and Development (IATED). 
Kapaniaris, A., \& Papadimitriou, E. (2012). Informatics Literacy in the Digital School. (pp. 31,36,37). Thessaloniki: Ziti.

Kapaniaris, A., Gasouka, M., Zisiadis, D., Papadimitriou, E., Kalogirou, E. (2013). Learning Object Design and Development in Folklore Education Using Web 2.0 Tools. 3rd International Conference on Human \& Social Sciences. Rome: Mediterranean Center of Social and Educational Research.

Kapaniaris, A., Vainas, K., Papadimitriou, E., Valatsou, G. (2010). The electronic book (ebook) as a tool of problem centred teaching. In Tseles, D. (Ed.), International Synergy in Energy, Environment, Tourism and contribution of Information Technology in Science, Economy, Society and Education (e R A - 5 - The SynEnergy Forum), Piraeus: T.E.I. of Piraeus.

Melhuish, K. \& Falloon, G. (2010). Looking to the future: M-learning with the iPad. Computers in New Zealand Schools. Learning, Leading, Technology, 22(3), 1-16.

Mori, K., Ballagas, R., Revelle, G., Raffle, Horii, H., Spasojevic, M. (2011). Interactive Rich Reading: Enhanced Book Reading Experience with a Conversational Agent. 19th ACM international conference on Multimedia: (pp.825-826). New York: ACM.

Pedagogical Institute - Interdepartmental Committee for the cultural autonomy of the school and the dialogue on education (2009). Proposal for the design and introduction of e-books in education. Retrieved June 25, 2013, from http://www.pischools.gr/paideia_dialogos/eBook.pdf

Thomas, N., Carroll, F., Kop, R. \& Stocking, S. (2012). iBook learning experience: the challenge of teaching computer architecture to first year university students. WORLDCOMP'12- The 2012 World Congress in Computer Science, Computer Engineering, and Applied Computing, Las Vegas, USA: World Academy of Science. Retrieved June 25, 2013, from http://elrond.informatik.tufreiberg.de/papers/WorldComp2012/EEE2439.pdf

Vasileiou M., Hartley, R. Rowley J. (2009). An overview of the e-book marketplace. Online Information Review, 1(33), 173 - 192. 